\title{
Mulheres e territórios vividos em contextos rurais: um olhar sobre a política de desenvolvimento territorial ${ }^{*}$
}

\author{
Emília Pietrafesa de Godoi** \\ Vilênia V. Porto Aguiar***
}

\section{Resumo}

A concepção de "desenvolvimento territorial" se tornou, em anos recentes, um balizador das formas de atuação do Estado na promoção de políticas de desenvolvimento e de combate à pobreza no Brasil. Desse modo, a abordagem territorial passou a ser utilizada como referência para uma estratégia de apoio ao desenvolvimento rural, por meio da implementação de ações abrangidas pelo então Programa de Desenvolvimento Sustentável de Territórios Rurais. Considerando o protagonismo das mulheres na conformação dos "territórios rurais", propomos, neste artigo, confrontar o conceito de território que baliza as ações do Programa de Desenvolvimento Sustentável de Territórios Rurais e a maneira como o território se configura nas e através das práticas cotidianas dessas mulheres.

Palavras-chave: Mulheres, Território, Políticas de Desenvolvimento.

\footnotetext{
* Recebido em 06 de novembro de 2017, aceito em 03 de julho de 2018.

** Professora do Departamento de Antropologia, Universidade Estadual de Campinas (Unicamp), Campinas, SP, Brasil. emilia.pietrafesa@gmail.com / https://orcid.org/0000-0001-8132-010X

****B Bolsista de pós-doutorado PDJ/CNPq no Programa de Pós-Graduação em Sociologia Política da Universidade Federal de Santa Catarina, vinculada ao Núcleo de Estudos sobre Agricultura Familiar, Universidade Federal de Santa Catarina (UFSC), Florianópolis, SC, Brasil. vileniap@gmail.com / https://orcid.org/0000-0001-7788-7218
} 
Women and Territories Lived in Rural Contexts:

a View on Territorial Development Policy

\begin{abstract}
The concept of "territorial development" has become, in recent years, a guide to the State's ways of promoting development policies and fighting poverty in Brazil. Thus, the territorial approach began to be used as a reference for a strategy to support rural development, through the implementation of actions covered by the Program for the Sustainable Development of Rural Territories. Considering women's role in shaping "rural territories", we propose, in this article, to confront the concept of territory that guides the actions of the Program of Sustainable Development of Rural Territories and the way in which the territory is configured in and through these women's daily practices.
\end{abstract}

Keywords: Women, Territory, Development Policies. 


\section{Um debate sobre território e a institucionalização de "territórios rurais" como política de desenvolvimento}

São vários os debates a nos lembrar da polifonia do conceito de território não somente entre distintos campos do conhecimento, como a Antropologia, a Geografia, a Ciência Política, a Sociologia, a Economia e a História, mas também no interior de um mesmo campo (Haesbaert, 2009; Lefebvre, 2000; Little, 2002; Raffestin, 1988; Sack, 1986; Pietrafesa de Godoi, 2014, para citar alguns autores, que trazem estes debates). Nas reflexões que se seguirão, além de ter em conta essa polifonia, há que se considerar, sobretudo, a distinção entre os diferentes estatutos do conceito, quer enquanto categoria analítica, usado como instrumento de análise por distintos campos do conhecimento, quer enquanto categoria operacional, a ordenar e orientar ações como as intervenções do Estado por meio de políticas públicas (Carneiro; Rocha, 2007). Este artigo coloca sob análise a política brasileira de desenvolvimento territorial rural e o lugar da mulher nesse programa, nos levando à constatação de que a política condiciona e impõe limites a dinâmicas territoriais específicas e se sobrepõe, muitas vezes, a outros entendimentos dos lugares de vida e trabalho das pessoas a que tais políticas se destinam.

Começaremos pelo entendimento e pelos usos do conceito de território entre cientistas sociais. Além da mencionada polissemia, há um atributo da territorialidade que precisa ser enfatizado. Ela é plural, uma vez que se reporta, como propomos, a processos de construção de territórios, isto é, de apropriação, controle, usos e atribuição de significados - não necessariamente nessa ordem - sobre uma parcela do espaço que é transformada em território. Dessa concepção já se depreende um aspecto importante também enfatizado por vários estudiosos, o território não diz respeito somente à materialidade do espaço, pois não há território exterior a relações sociais (Haesbaert, 2009; Pietrafesa de Godoi, 2014). Quando falamos na territorialidade enquanto processo de construção de um território, o aspecto processual merece destaque, pois confere ao território um caráter plástico, 
isto é, em permanente conformação; não se refere, pois, a uma construção definitivamente acabada. Concebendo assim o território, estamos longe de concepções que o compreendem como sinônimo de espaço ou espacialidade, ou como simplesmente "fonte de recursos" disputados ou, ainda, de elementar "apropriação da natureza", crítica também feita por Haesbaert (2009).

A despeito de todo o debate nas ciências sociais que enfatiza os aspectos acima mencionados, constata-se que o entendimento mais difundido é aquele que se refere às relações jurídico-politicas, em que o território é visto como um espaço delimitado e controlado no qual se exerce um determinado poder quase sempre relacionado ao poder do Estado. De fato, a dimensão política $e$ as relações de poder são muito importantes na compreensão de territorialidades específicas e, por consequência, do território. A questão é: qual concepção de poder e de política? Autores como Raffestin (1993; 1988) e Sack (1986), que concebem o território dentro dessa chave, não restringem a dimensão política ao papel dos Estados, nem ignoram a interseção com as dimensões econômica e cultural das sociedades (Haesbaert, 2009), entendem as relações de poder como imanentes às várias dimensões da vida social. É, no entanto, a assimilação da dimensão política às dimensões jurídica $e$ estatal, $e$ acrescentaríamos administrativa, que leva grande parte do pensamento social a associar diretamente a noção de território às práticas territoriais dos Estados-nação. ${ }^{1}$

1 De fato, os Estados-nação surgem promovendo uma "territorialização" no sentido de controle do acesso a uma área geográfica e de classificação das pessoas conforme seu lugar de nascimento, e não exageramos dizendo que a existência "legal" dos indivíduos passa a depender de sua "condição territorial nacional", como disse Paul Little (2002). O que ocorre é que o ordenamento social e físico-espacial que se impõe com o surgimento dos Estados-nação vai se converter em forma hegemônica tornando invisíveis e deslegitimando várias das distintas formas de territorialidade costumeiramente constituídas. 
Vamos reter o mencionado aspecto processual que confere historicidade ao território em permanente conformação, por oposição à ideia de um espaço delimitado e controlado no qual se exerce um determinado poder. Ora, mesmo que se tome como unidade de observação pequenas unidades espaciais, se o foco forem as ações e interações entre pessoas, constatar-se-á, por um lado, que esses espaços não são totalidades homogêneas $e$ atemporais $e$, por outro, que as pessoas em geral estão em fluxo entre aldeias, entre sítios, entre o campo e a cidade, entre cidades, entre países. Muitas vezes, a própria reprodução de grupos domésticos e residenciais, que até podem coincidir com unidades territoriais, exige que alguns de seus membros migrem, sem com isso significar perda do território; ao contrário, suas vidas passam a ser multilocais e seus territórios de vida e de trabalho descontínuos (Sahlins, 1997). Muitas vezes, essa mobilidade além de ser estratégica para a reprodução dos grupos que vivem, por exemplo, em uma terra escassa, é ao mesmo tempo estrutural e acompanha todo o processo de transformação da sociedade. Uma consequência desse ponto de vista é a percepção do "sentido relacional do território" que diverge de uma leitura de espaço como enraizamento e estabilidade (Pietrafesa de Godoi, 2014). Com essa perspectiva traçada, passemos a considerar a política brasileira de "desenvolvimento territorial rural".

Em 2003, foi criado o Programa de Desenvolvimento Sustentável de Territórios Rurais (PRONAT) e, em função dele, foi instituída, em 2004, a Secretaria de Desenvolvimento Territorial (SDT), que passou a integrar a estrutura organizacional do Ministério do Desenvolvimento Agrário (MDA), criado em 1999.²

2 No ano de 2016, o MDA foi extinto. Com a sua extinção, foi criada a Secretaria Especial de Agricultura Familiar e do Desenvolvimento Agrário, a qual encontra-se subordinada à Sub-Secretaria de Desenvolvimento Rural, que veio a substituir a Secretaria de Desenvolvimento Territorial, também extinta. A mencionada subsecretaria manteve, contudo, como estratégia de atuação a abordagem territorial do desenvolvimento expressa no Programa de Desenvolvimento Sustentável de Territórios Rurais. 
À Secretaria de Desenvolvimento Territorial coube a implementação da política pública de desenvolvimento territorial, pelo PRONAT, por meio do qual promoveu o processo de construção e implantação de Planos Territoriais de Desenvolvimento Sustentável (PTDS) em regiões onde predominavam agricultores(as) familiares e beneficiários da reforma agrária. Foi a partir da implantação desse programa que foram definidos os "territórios" que seriam passíveis de serem beneficiários de políticas públicas (Corrêa, 2009). A noção de território que passou a sustentar o programa foi assim definida no Marco Referencial ${ }^{3}$ :

Um espaço físico, geograficamente definido, geralmente contínuo, compreendendo cidades e campos, caracterizado por critérios multidimensionais, tais como o ambiente, a economia, a sociedade, a cultura, a política $e$ as instituições, e uma população, com grupos sociais relativamente distintos, que se relacionam interna e externamente por meio de processos específicos, onde se pode distinguir um ou mais elementos que indicam identidade e coesão social, cultural $e$ territorial (MDA/SDT, 2005:7).

De início destacamos que, nessa definição, o aspecto processual do território em permanente conformação pelas pessoas que fazem dele seu lugar de vida e trabalho não merece consideração, e a dimensão física geograficamente definida é o que ganha força. Também o aspecto sincrônico é destacado em detrimento de uma abordagem mais diacrônica e logo uma equação se estabelece - um território: um ambiente: uma população: uma cultura. Tal concepção que orientou a

3 O Marco Referencial para Apoio ao Desenvolvimento de Territórios Rurais, publicado em junho de 2005, foi um documento institucional elaborado pela equipe técnica da SDT com a finalidade de orientar a implementação das ações abrangidas pelo Programa de Desenvolvimento Sustentável de Territórios Rurais. 
constituição dos "territórios rurais" ${ }^{4}$ e também a mobilização em torno deles, compreendia que o "desenvolvimento" desses espaços implicava na existência de capital social, na gestão social e no fortalecimento das "institucionalidades territoriais", como elementos de um processo que deveria contribuir para o empoderamento das pessoas e instituições.

Assim, as institucionalidades territoriais se configuraram como:

Espaços (fóruns, conselhos, comissões, comitês, consórcios, articulações e arranjos institucionais diversos) de expressão, discussão, deliberação e gestão, que congregam a diversidade de atores sociais e cuja atenção é voltada à gestão social das políticas $e$ dos processos de desenvolvimento (MDA/SDT, 2005:11).

A gestão social, por sua vez, pressupunha o envolvimento do conjunto dos atores sociais, homens e mulheres de um "território" estabelecido pelo programa, não apenas nos espaços de deliberação e consulta das políticas para o desenvolvimento, mas também em um conjunto de iniciativas que abarcava desde a mobilização desses(as) agentes e fatores locais até a implementação e a avaliação das ações planejadas, passando pelas etapas de diagnóstico, elaboração de planos, negociação de políticas e projetos (MDA/SDT, 2005). De acordo com o Marco Referencial, isso implicava na mobilização do capital social existente, ou seja, na mobilização de relações (pessoais, sociais e institucionais) baseadas em processos geradores de confiança, reciprocidade e cooperação; e de colaboração entre as forças locais, passíveis de serem mobilizadas visando o desenvolvimento do "território".

${ }^{4}$ O Programa de Desenvolvimento Sustentável de Territórios Rurais começou a operar em 2004 em 65 territórios, passando para 118, em 2006; 164, em 2010 e, a partir de 2013, passou a abranger 238 territórios rurais, compostos por mais de 3,5 mil municípios. 
Ainda de acordo com o Marco Referencial (MDA/SDT, 2005), do ponto de vista das diretrizes que balizavam as estratégias de apoio ao "desenvolvimento sustentável dos territórios rurais", esses deveriam ser compreendidos como espaços socialmente construídos, locus de manifestação de uma diversidade cultural e ambiental. Como tal, eles envolveriam uma diversidade de atores com interesses nem sempre convergentes que expressariam limites $e$ potencialidades para a promoção de processos de desenvolvimento rural sustentável, que, por sua vez, adquiriam características próprias conforme os "territórios rurais", os estados $e$ as regiões do país, e também de acordo com as diferentes demandas das populações envolvidas, segundo o espaço onde se situam.

Contudo, a seleção dos "territórios rurais" foi pautada em parâmetros nem sempre coerentes com as diretrizes postas. Inicialmente, eles foram caracterizados a partir da base de dados do Instituto Brasileiro de Estatística e Geografia (IBGE) referente aos municípios e às microrregiões geográficas do Brasil. Tal caracterização identificou três grupos de territórios - urbanos, intermediários e rurais, sendo estes últimos definidos como "microrregiões geográficas que apresentam densidade demográfica menor que 80 habitantes/ $/ \mathrm{km}^{2}$ e população média por município de até 50 mil habitantes" (Brasil, 2005:16). Foram, assim, identificados 450 aglomerados municipais com características rurais. A partir daí foi estabelecida a priorização de atendimento de acordo com o foco de atuação do Ministério do Desenvolvimento Agrário, qual seja, "concentração de agricultores familiares; concentração de famílias assentadas por programas de reforma agrária; concentração de famílias de trabalhadores rurais sem-terra, mobilizados ou não" (Brasil, 2005:17). Em diálogo com os governos estaduais e a sociedade civil local, os territórios foram ordenados, a partir dos seguintes critérios: densidade e atividade de capital social, entendido como formas associativas existentes nos "territórios rurais"; a convergência de interesses institucionais e de participação da sociedade civil e de governos estaduais; existência de áreas prioritárias de ação do governo federal nos 
estados; incidência de programas, projetos e planos de desenvolvimento de caráter regional (Brasil, 2005:17). Os Conselhos Estaduais de Desenvolvimento Rural Sustentável foram tomados como fóruns preferenciais para esse ordenamento.

Nessa perspectiva, os "territórios rurais" podem ser compreendidos mais como espaços politicamente negociados, cujo campo de intervenção é delimitado pela identificação de uma população e uma base física, do que propriamente como um espaço de vida e trabalho construído socialmente. Esse aspecto pode comprometer uma outra diretriz apresentada pelo Marco Referencial que aponta que a participação da diversidade de atores sociais envolvidos num dado território, deve ser estimulada nos processos de elaboração, planejamento, implementação $e$ gestão do desenvolvimento sustentável dos "territórios rurais", considerando as dimensões étnico-raciais, de gênero e geracional.

A questão que se coloca é: como fazer parte dos processos de gestão de um território sem que se sinta a ele pertencente? Afinal, as mulheres rurais experimentam seu gênero também através do território. Algo expresso na fala de uma liderança ao ser questionada sobre a participação das mulheres nas políticas territoriais:

Quem vai elaborar políticas públicas ou quem for elaborar um plano de desenvolvimento territorial, não pode pensar no território com algo único, tem que pensar primeiro nesta diversidade de gente, de jeito de fazer, de jeito de pertencer a um lugar e até na diversidade de vegetação, de natureza. Por que se a gente está buscando alternativas, também estamos buscando soluções alternativas para as diversidades, para as realidades que são muitas, $e$ a gente sabe muito bem que não são é uma só (R.S., 35 anos, 2016).

Antes de prosseguirmos, cabe aqui abrir um parêntese para elucidar dois pontos. O primeiro deles é que ao utilizarmos a expressão genérica "mulheres rurais", não estamos buscando definir um campo identitário a priori, mas utilizando um recurso, digamos assim, para agregar coerência discursiva. Não se trata, 
pois, de uma categorização estanque e homogeneizante, mas antes, um termo aglutinador de uma pluralidade e uma diversidade de mulheres que povoam os mais diferentes territórios rurais e que se nomeiam das mais diferentes formas, seja como agricultoras familiares, trabalhadoras rurais, assentadas, quebradeiras de côco, seringueiras, extrativistas, ribeirinhas, pescadoras, quilombolas ou, ainda, como camponesas.

Não obstante, se fazemos aqui o uso da categoria mulher, o fazemos incorporando todas as críticas propostas pelos "estudos de gênero" às abordagens da Antropologia da Mulher dos anos 1970, ao questionar o caráter universal e essencialista atribuído a essa categoria, que assim opera "sob rasura" (Hall, 2009)..$^{5}$ Fazemos igualmente uso de "gênero" como categoria analítica conforme sugerido por Scott (1995), e partilhamos com Brah (2006:131) a ideia de que:

Nuestro genero se constituye y se representa de distintas formas segun nuestra ubicacion diferencial dentro de las relaciones globales de poder. Nuestra insercion en estas relaciones globales de poder se realiza a traves de una multitud de procesos económicos, políticos e ideológicos. Dentro de estas estructuras de relaciones sociales no existimos simplemente como mujeres, sino como categorias diferenciadas, tales como "mujer de clase trabajadora", "mujer campesina" o "mujer migrante". Cada elemento hace referencia a una especificidad en la condition social. Las vidas reales se forjan mediante una compleja articulacion de estas dimensiones. Hoy es algo axiomatico en la teoria y la practica feminista que la "mujer" no es una

${ }^{5}$ Segundo Hall (2009), colocar conceitos-chave "sob rasura" indica que "eles não servem mais" - não são mais "bons para pensar" - em sua forma original, não reconstruída. Mas, uma vez que eles não foram dialeticamente superados e que não existem outros conceitos inteiramente diferentes que possam substituí-los, não existe nada a fazer senão continuar a se pensar com eles - embora agora em suas formas destotalizadas e desconstruídas (Hall, 2009:104). 
categoria unitaria. Aun asi, esto no significa que la categoria en si misma carezca de sentido. El signo "mujer" tiene su propia especificidad constituida dentro de y a traves de configuraciones historicamente espetificas de relaciones de genero.

Com isso queremos ressaltar que compreendemos que as mulheres aqui referidas são construídas a partir de contextos específicos, e constituídas por múltiplas posições plurais (ou posicionalidades), contraditórias e contingentes (Butler, 2003; 1998; Brah, 2011), e dentro de significados e de representações culturais que encontram-se mascarados por relações de poder (Costa, 2000:57). Compreendemos que a posicionalidade assumida por cada uma das nossas interlocutoras está invariavelmente ligada à sua localização social, cultural, geográfica, econômica, sexual, etc., a partir da qual elas interpretam o mundo e fundamentam as suas falas (Aguiar, 2015).

$\mathrm{E}$ este é justamente o segundo ponto que queremos elucidar: a produção das falas utilizadas neste artigo. Elas são derivadas de uma pesquisa que objetivou a realização de um diagnóstico visando identificar os limites e desafios das políticas territoriais na vida das mulheres rurais. Tal diagnóstico fez parte de um trabalho de consultoria realizado, em 2016, para a Diretoria de Políticas para as Mulheres Rurais do extinto MDA. Para construí-lo foram realizadas entrevistas semiestruturadas com representantes de alguns movimentos e organizações de mulheres rurais presentes, como delegadas, na $4^{\text {a }}$ Conferência Nacional de Politicas para as Mulheres (15 e 18 de março de 2016) e na $2^{\mathrm{a}}$ Conferência Nacional de Assistência Técnica e Extensão Rural (de 31 de maio a 3 de junho de 2016). Complementarmente, as entrevistas também contemplaram delegadas que, embora, não tivessem vínculo algum com movimentos ou organizações específicas de mulheres, haviam sido eleitas nas conferências territoriais. A escolha das interlocutoras se deu de forma aleatória, embora procurando abarcar a diversidade de sujeitos presentes nas conferências, de acordo com a idade, a cor e a categoria 
identitária com a qual buscavam ser identificadas naqueles espaços (agricultoras, sem-terras, quilombolas, pescadoras etc.). Trechos dessas falas serão reproduzidas neste artigo, dando suporte ao diálogo que nos propomos a estabelecer aqui. Contudo, por razões éticas, preservaremos a identificação nominal das entrevistadas, sendo elas identificadas apenas pelas iniciais dos seus nomes.

Feita esta breve digressão, voltemos às diretrizes, apresentadas pelo Marco Referencial, como balizadoras das estratégias de apoio ao "desenvolvimento sustentável dos territórios rurais". Algumas delas apontam para a priorização da redução das desigualdades econômicas e sociais, assim como para a importância da dinamização econômica nos "territórios rurais". Ambos, Secretaria de Desenvolvimento Territorial e Programa de Desenvolvimento Sustentável de Territórios Rurais, foram criados, assim, com a missão de valorizar a agricultura familiar, enfrentar a pobreza rural $e$ as desigualdades regionais, integrar as políticas públicas com um viés de intersetorialidade $e^{6}$, e promover a dinamização das economias nos "territórios rurais", tomando com fios condutores, a diversidade, a pluralidade e a autonomia dos atores sociais, homens e mulheres. Mas como as falas atestam, a política condiciona ações, impõe e encontra limites.

Eu acho que tem algumas políticas que estão muito focadas na ideia de fomento da produção. Não considera o modo como a gente se organiza, o nosso sistema de produzir, o nosso jeito, as técnicas que a gente utiliza, uma coisa bem focada na produção e no mercado. Mas tem outras que já é mais ampla, considera a questão da educação ou vão se preocupar com os recortes de gênero, por exemplo,

\footnotetext{
${ }^{6}$ A intersetorialidade consiste numa ação que integra diferentes políticas públicas visando solucionar problemas que atingem parte expressiva da população de um dado território. Ela pressupõe uma concepção de gestão das políticas públicas que envolva o planejamento, a execução e o controle social na prestação de serviços públicos.
} 
fortalecendo a participação das mulheres nos processos produtivos, nos processos organizativos; temos políticas de saúde, políticas sociais mais amplas. A política de desenvolvimento territorial, pelo menos na teoria, parece ter como base a organização deste segmento da agricultura familiar, incentiva a participação e tal, mas no fim, ela também vai cair também numa ideia produtivista, e a gente não consegue se livrar facilmente disto, porque tem sempre um projeto territorial de desenvolvimento que é aprovado, de infraestrutura nos territórios que também tem uma tendência a enfatizar a produção (...) Nós trabalhamos tudo artesanalmente, nós plantamos, nós colhemos, tudo nós mesmos, na mão mesmo, mas não tem aquela máquina da indústria para mecanizar a terra, não tem essa coisa toda, quem faz é a gente mesmo, aí o desenvolvimento rural sustentável, mas na hora de discutir o recurso é uma briga, tem que sair articulando as mulheres pra botar dentro do Comitê do Território da Cidadania pra discutir o recurso, é um tal de "liga pra não sei quem... não tem passagem... a gente arruma, tira do bolso" e assim vai (R.S., 35 anos, 2016).

De acordo com Grisa (2013), as ações de desenvolvimento para as mulheres contempladas pelos projetos estratégicos que enfatizam a dimensão socioeconômica nas políticas de desenvolvimento territorial não chegavam a 1\% em 2013 (Grisa, 2013). A fala acima destacada, embora falando dos recursos destinados aos projetos, é reveladora do quanto essas políticas pouco contemplam as mulheres na sua implementação: "é uma briga, tem que sair articulando as mulheres pra botar dentro do Comitê do Território da Cidadania pra discutir o recurso". Outro aspecto revelador dessa fala é a ênfase "numa ideia produtivista, e a gente não consegue se livrar facilmente disto, porque tem sempre um projeto territorial de desenvolvimento que é aprovado, de infraestrutura nos territórios que também tem uma tendência a enfatizar a produção". Muito se confundiu a geração de renda, um dos objetivos das políticas públicas, com uma concepção produtivista, que acabou por desconsiderar orientações culturais 
próprias de contextos rurais de agricultores(as) familiares, orientações que dizem respeito a uma ética de relacionamentos entre pessoas e entre elas e elementos da natureza como a terra $e$ a água, para ficar em alguns deles. Além de não se levar em conta o que estamos chamando de uma "ética de relacionamentos" que envolve desde a escolha do que plantar até as relações que envolvem hierarquia entre pessoas, mas também igualdade em honra de pais e chefes de família, e um grande apreço pela autonomia familiar - os agricultores(as) têm sempre que estar atentos ao que poderia ser aprovado pelas instâncias decisórias (desde as prefeituras até o Conselho Estadual de Desenvolvimento Rural Sustentável). Como advertem Carneiro e Rocha (2007:20)

\begin{abstract}
o entendimento de que suas demandas não são consideradas prioritárias por esses fóruns leva ao descrédito sobre o poder de decisão dos próprios agricultores $e$, por conseguinte, coloca em dúvida a eficácia da política participativa.
\end{abstract}

\title{
II.As mulheres rurais na política territorial
}

Em 2011, por meio da Resolução $\mathrm{n}^{\circ}$ 80, de 19 de maio, é criado o Comitê Permanente de Promoção de Políticas para as Mulheres Rurais do Conselho de Desenvolvimento Rural Sustentável - CONDRAF, do Ministério do Desenvolvimento Agrário. De acordo com a própria resolução, tal medida foi tomada por considerar que, ao longo da história, as políticas públicas não levaram em conta as desigualdades de gênero no meio rural $e$ não desenvolveram estratégias para estimular a inclusão das mulheres na economia. Por outro lado, havia a necessidade de consolidar e ampliar as políticas públicas para as mulheres, sintonizadas com os compromissos assumidos para a democratização no Brasil Rural a partir da promoção da igualdade de gênero. A resolução partia, ainda, da consideração de que as ações a serem desenvolvidas deveriam estar articuladas a uma política pública integrada para o desenvolvimento rural sustentável, com enfoque nas atividades produtivas e nas políticas 
agrárias, com democracia de gênero. E por fim, considerava a necessidade da construção de uma estratégia de fortalecimento dos espaços coletivos democráticos, reforçando a presença e a participação das mulheres rurais (CONDRAF, 2011).

De certa forma, tal resolução reconhecia uma lacuna nos chamados colegiados territoriais ${ }^{7}$ relativa a um segmento da população - as mulheres rurais, que viviam no campo, mas que não estavam suficientemente incorporadas aos espaços que definem e deliberam sobre a gestão do que foi definido como território. O fortalecimento de "institucionalidades territoriais" implicou, assim, na construção de estratégias visando a redução das desigualdades de gênero no PRONAT, o que levou à composição de uma agenda de "Desenvolvimento Rural Sustentável Solidário" que estabelecesse uma relação com as Políticas para Mulheres Rurais, com o fim de garantir a participação dessas mulheres e a discussão a partir dos territórios onde vivem. $\mathrm{O}$ fortalecimento e a capacidade de lograr êxito dessas estratégias tinham como pressuposto o diálogo entre a SDT e a Diretoria de Política para as mulheres rurais.

\section{A diretoria de políticas para as mulheres rurais}

Em 2003, paralelamente à criação da Secretaria de Política para as Mulheres (SPM), foi criada, no Ministério do Desenvolvimento Agrário (MDA), o Programa de Promoção da Igualdade de Gênero, Raça e Etnia (PPIGRE), como resultado de uma reformulação do antigo Programa de Ações Afirmativas para

\footnotetext{
7 Colegiados territoriais são institucionalidades responsáveis pelos processos de execução da gestão social do desenvolvimento territorial e se constitui no espaço de maior referência na política territorial, tanto pela possibilidade de exercício da articulação dos agentes envolvidos nos processos produtivos, como também na articulação com outros temas, atores e processos que constituem a realidade local (TIMM, 2014). Nesses espaços se dá a participação dos grupos sociais envolvidos nos processos de desenvolvimento. Cada "território" tem seu colegiado constituído.
} 
Promoção da Igualdade e Oportunidade de Tratamento entre Homens e Mulheres, existente desde 2001. Segundo Siliprandi \& Cintrão (2015) "o PPIGRE centrou sua atuação em uma revisão da legislação e dos mecanismos regulatórios dos programas existentes, assim como na criação de novas políticas, com vistas a um melhor atendimento às demandas das mulheres" funcionando na prática como

uma assessoria de gênero àquele Ministério, e ao governo Federal como um todo, buscando facilitar o acesso das mulheres rurais ao conjunto de políticas existentes $e$ promovendo um diálogo permanente com os movimentos de mulheres (Siliprandi; Cintrão, 2015:184).

Em 2010, o PPIGRE passou por uma reformulação com a criação da Assessoria Especial de Gênero, Raça e Etnia (AEGRE), ligada diretamente ao gabinete do MDA e transformada no final desse mesmo ano em uma Diretoria de Políticas para Mulheres Rurais (DPMR) ${ }^{8}$, com orçamento e pessoal próprios, e o mesmo status das demais diretorias do MDA. Ainda segundo Siliprandi \& Cintrão (2015:184):

Estas mudanças institucionais significaram um aumento de poder e um reconhecimento, no âmbito daquelas instâncias de governo, da importância de ações afirmativas. Os novos arranjos institucionais redundaram em arcabouços normativos e permitiram uma prática cotidiana de diálogo e parcerias envolvendo os diferentes órgãos governamentais e entidades representativas das mulheres.

A Diretoria de Políticas para Mulheres Rurais canalizava parte significativa dos seus esforços para três programas

8 A DPMR deixou de existir após a extinção do Ministério do Desenvolvimento Agrário, em 2016. Nesse mesmo ano, foi criada, no âmbito da Subsecretaria de Desenvolvimento Rural, a Coordenação de Política para Mulheres Rurais, Juventude, Povos e Comunidades Tradicionais. 
fundamentais: Documentação da Trabalhadora Rural, Organização produtiva e Assistência técnica e extensão rural setorial (ATER), e havia um empenho de que ações envolvendo esses programas acontecessem de forma articulada e acessível às mulheres rurais. Desse modo, esforços foram feitos para que essas ações acontecessem a partir dos "territórios rurais", fortalecendo assim, não só as atuações $e$ intervenções das mulheres nesses espaços, mas a própria política territorial.

Partia-se, primeiramente, do questionamento do lugar atribuído à mulher na agricultura familiar $e$ da invisibilidade do seu trabalho produtivo, marca de uma divisão sexual do trabalho que se expressa na sua responsabilização pelo trabalho doméstico (e de cuidados), e na concentração em atividades na esfera produtiva, voltadas para o autoconsumo familiar (a criação de aves e pequenos animais, a horticultura e a floricultura) apesar de ser significativa a sua participação também na chamada lavoura; em segundo lugar, do reconhecimento da mulher rural como sujeito produtivo, fundamental na dinamização da economia rural. Além disso, considerava-se que o acesso das mulheres à infraestrutura produtiva era pequeno, assim como o era a proporção de projetos no PRONAT dedicados especificamente a determinados públicos, como as mulheres, segmento social cuja presença nos "territórios rurais" é igualmente pequena. Por fim, as ações buscavam estimular a articulação, a organização $e$ a participação das mulheres rurais nos colegiados territoriais, a partir de uma ação de política pública. Partia-se de uma constatação: a participação das mulheres nas instâncias colegiadas era frágil $e$ precisava ser estimulada de alguma forma.

A "Articulação e Mobilização Territorial" foi a estratégia adotada pela Diretoria de Políticas para Mulheres Rurais para promover $\mathrm{o}$ apoio às mulheres rurais na política de desenvolvimento territorial, articulando ações que potencializassem a distribuição $e$ o acesso às políticas públicas com perspectiva de gênero, e com isso, ampliar e fortalecer a participação das mulheres rurais na política de desenvolvimento territorial e nos espaços de gestão social, com vistas a igualar a 
renda $e$ o acesso a direitos entre mulheres $e$ homens nesse segmento, buscando promover a inclusão socioprodutiva, o acesso às políticas públicas, aos direitos sociais e à cidadania.

\section{A participação das mulheres nas políticas de desenvolvimento territorial}

Como tratado no início destas reflexões, o território não se refere a um espaço homogêneo, mas a porções do espaço que apresentam situações concretas, resultantes da sua história, das forças políticas que ali atuam e dos projetos de que são portadores seus diferentes atores sociais, homens e mulheres. Assim, quando consideramos as dinâmicas territoriais da perspectiva da participação de homens e mulheres e do protagonismo social, é importante atentar para as suas diversas trajetórias, para as suas experiências sociais e institucionais; e a complexidade histórica, política, econômica, social e cultural que delineia a sua realidade.

Enquanto construção social, o território é também uma construção política, pois implica relações de poder entre sujeitos, com interesses distintos, que assumem papel decisivo nos projetos de intervenção do Estado como políticas públicas para o "desenvolvimento". Envolve, portanto, relações de poder entre grupos e segmentos sociais marcados não apenas pelo pertencimento a uma determinada classe social, em que o conflito maior se localiza nos interesses econômicos, mas também pelo pertencimento étnico-racial, geracional, de gênero, entre outros, os quais muitas vezes revelam dimensões das desigualdades existentes.

Uma das desigualdades sociais fortemente presentes na sociedade em geral, e em particular nos "territórios rurais", é a desigualdade de gênero, o que acaba por se refletir nos espaços institucionais de participação e decisão dos programas voltados aos "territórios rurais". De acordo com Butto (2010:218), o "desenvolvimento rural, pensado a partir das relações de gênero, não pode se limitar a estimular a participação social simplesmente, posicionamento corrente entre alguns adeptos da abordagem territorial", sendo "necessário considerar as distintas dimensões 
presentes na desigualdade que as mulheres vivenciam no campo". Nesse sentido, para a referida autora, para refletir sobre as relações de gênero nas dinâmicas territoriais é necessário integrar todas as quatro dimensões fundamentais do desenvolvimento sustentável - as dimensões sociocultural, político-institucional, econômica e ambiental:

$\mathrm{Na}$ dimensão econômica e ambiental, é necessário considerar que, embora as mulheres sejam detentoras de conhecimentos sobre uso e manejo da biodiversidade, têm menor acesso aos bens da natureza $e$ aos recursos financeiros. Este fato repercute na ausência e/ou menor acesso à terra e à renda. Além disso, sua inserção não monetária as concentra em atividades voltadas para o autoconsumo. Deve-se considerar também que assumem de forma quase exclusiva o trabalho doméstico e de cuidados, gerando maior jornada de trabalho, mesmo que as estatísticas oficiais insistam em afirmar o contrário. Também enfrentam condições precárias para a realização do trabalho doméstico - a exemplo dos problemas gerados pela escassez de água em suas residências e de falta de gás - e menor disponibilidade para atividades geradoras de renda monetária. A forma de inserção econômica das mulheres produz uma representação do seu trabalho como atividade secundária e marginal, mesmo que sem 0 trabalho delas não seja possível garantir a reprodução física e social da agricultura familiar e do seu papel decisivo na manutenção da biodiversidade e preservação ambiental (Butto, 2010:218).

Ainda de acordo com Butto (2010), a combinação da dimensão política com a econômica constitui o centro da análise do lugar das mulheres rurais no "desenvolvimento", de modo que para entender a exclusão econômica das mulheres é preciso incorporar na análise os mecanismos políticos comumente presentes na manutenção da subordinação, expressando também a dimensão simbólica da desigualdade. E nesse sentido, além da família, os espaços públicos e o Estado são "decisivos na 
reprodução da desigualdade existente entre mulheres e homens rurais". $\mathrm{Na}$ análise do Butto:

Estas instituições se entrelaçam da seguinte forma: na família, os homens se legitimam como seu representante perante o mundo público e o Estado - é o chamado Chefe de Família; as mulheres só adquirem esta condição quando não contam com a figura masculina no grupo familiar. $\mathrm{O}$ Estado e os espaços públicos elaboram política pública $e$ atuam considerando o que seriam as necessidades da família e não de cada um dos indivíduos independente da sua condição civil e familiar. Reforçam a ideia de que as necessidades são iguais $e$ que se relacionando com o "titular" todos serão beneficiados. Essa mesma visão prevalece nos espaços públicos que não consideram as desigualdades econômicas, nem o privilégio dos homens nas decisões $e$ acesso a bens e recursos. Isto ajuda a entender porque as mulheres estão menos representadas em espaços públicos e na sociedade civil e porque as suas demandas/necessidades não integram de forma satisfatória com a agenda de lutas pelo desenvolvimento rural (Butto, 2010:219).

Vê-se, pois, diluídos os interesses, sonhos e projetos de mulheres que vivem nos espaços rurais. Elas não são vistas $e$ entendidas como atores singulares nos projetos de desenvolvimento do Estado. A desigualdade que se expressa em todas essas dimensões acaba por incidir sobre o protagonismo das mulheres nas "instâncias territoriais", de modo a expressar também uma desigualdade na participação entre homens $e$ mulheres nesses espaços. Esse problema não se resolve com o mero estímulo à participação, e sem o reconhecimento de necessidades, interesses, desejos e projetos desse importante segmento rural.

A desigualdade combinada à inexistência ou ao baixo protagonismo implica ainda na "invisibilidade" de certos grupos ou segmentos sociais. Aliás, alguns estudos identificam como um dos desafios da abordagem territorial, o fato de ela não conseguir 
"avançar mais em direção a um processo de empoderamento dos "invisíveis", isto é, homens e mulheres que não conseguem ter acesso, nem participação nas políticas territoriais, por não estarem, "necessariamente, bem representados, organizados, e que precisam ser incluídos", como é o caso, particularmente, das chamadas populações indígenas, das chamadas populações tradicionais (Leite et alii, 2008:152). Parte significativa dos agricultores familiares brasileiros que apresentam baixos rendimentos econômicos e não participam de movimentos sociais e sindicais são os que têm mais dificuldade de acesso às principais políticas públicas de desenvolvimento rural, em especial as de crédito e de extensão rural.

Esse público, somado aos assalariados agrícolas residentes nas periferias de pequenos municípios rurais (...) configura uma parcela significativa da população rural que não faz parte da sociedade civil, no sentido de não integrar ou não ser representado por nenhuma organização associativa, política ou sindical. Trata-se de uma população rural invisível que não compõe o público alvo de políticas públicas de cunho não assistencialista $e$ das intervenções, também de caráter público, empreendidas por organizações da sociedade civil (Boannal et alii, 2012).

Um segmento significativo dessa população é composta por mulheres rurais que vivem nos campos, cerrados e florestas, o que leva alguns estudos a enfatizar a necessidade de visibilizar o protagonismo dessas mulheres.

Foi realizado um diagnóstico, entre os meses de junho e outubro de 2009, pelas ONGs Sempre Viva Organização Feminista (SOF) e Centro Feminista 8 de Março (CF8) em parceria com a Diretoria de Políticas para as Mulheres (DPMR) do então Ministério do Desenvolvimento Agrário (MDA), sobre a implementação de 
políticas nos "territórios da cidadania". ${ }^{9}$ Com abrangência de 86 Territórios da Cidadania, de todas as regióes do país, foram realizadas 983 entrevistas, das quais $510 \mathrm{com}$ mulheres assentadas $e$ da agricultura familiar ${ }^{10}$. Nesta pesquisa, observou-se que embora as mulheres rurais apresentassem um grau significativo de participação nos territórios, essa participação não se reproduzia automaticamente em sua presença nas instâncias dos Territórios da Cidadania. Observou-se, ainda, que "as demandas $e$ preocupações das mulheres não foram tomadas em conta na maioria dos Planos de Desenvolvimento Territorial elaborados pelos colegiados", indicando que mesmo sendo ativas participantes de movimentos sociais e sindicatos, "os mesmos não tomam em conta a agenda das mulheres no cotidiano de seu trabalho" (Butto et alii, 2014:66).

O diagnóstico acima mencionado revelou que, em alguns "territórios", embora houvesse a participação de algumas lideranças de mulheres no colegiado territorial, representando seus movimentos sociais ou organizações da sociedade civil, poucas tinham conhecimento sobre a política de desenvolvimento territorial, a estrutura do colegiado e sua dinâmica de

9 Territórios da cidadania são chamados os territórios que integram o Programa Territórios da Cidadania (PCT) criado em 2008, com o propósito de superar a pobreza $e$ as desigualdades sociais no meio rural, incluindo as de gênero, raça $e$ etnia. Os critérios utilizados para definir e priorizar os territórios incluídos no programa consideraram um conjunto de fatores, dos quais destacam-se: a condição de já participar da política territorial do Ministério do Desenvolvimento Agrário (MDA), apresentar baixo Índice de Desenvolvimento Humano (IDH), possuir maior concentração de beneficiários do Programa Bolsa Família, assim como de agricultores familiares e assentados da reforma agrária, populações tradicionais, quilombolas e indígenas, apresentar convergência de programas de apoio ao desenvolvimento de distintos níveis de governo, possuir maior concentração de municípios de menor Índice de Desenvolvimento de Educação Básica e, pelo menos, um território por estado da federação (BRASIL, 2007).

${ }^{10}$ As outras entrevistas foram feitas com gestores e gestoras das políticas públicas do MDA para a igualdade de gênero nos âmbitos estadual e territorial; técnicos e técnicas de organizações não governamentais (ONGs) e extensionistas das entidades oficiais de ATER. 
funcionamento. Durante a $2^{\mathrm{a}}$ Conferência Nacional de ATER, ocorrida em 2016, ao entrevistar algumas delegadas ali presentes, chegamos a conclusões semelhantes (Aguiar, 2016). Mesmo aquelas que afirmavam participar das "plenárias territoriais" pouco sabiam sobre o funcionamento da política e da sua dinâmica. Elas nem mesmo sabiam dizer ao certo se o município onde moravam fazia parte do território, tampouco se as organizações nas quais elas atuavam tinham representantes no colegiado territorial. Não era incomum a constatação de que, embora várias organizações $e$ grupos produtivos de mulheres rurais atuassem nos espaços delimitados pelos "territórios rurais", não eram presentes nos Colegiados Territoriais.

Butto \& Hora (2014), em um artigo intitulado "Políticas Públicas para mulheres rurais no contexto dos territórios da cidadania", apontam que:

Dentre as dificuldades que enfrentam para ter participação ativa, as mulheres elencam a escassez de informações sobre o cronograma das reuniões, a ausência da capacitação dos membros dos colegiados sobre relações de gênero, o escasso envolvimento das mulheres na elaboração do Plano Territorial de Desenvolvimento Rural Sustentável (PTDRS), a ausência de atendimento aos grupos produtivos de mulheres rurais nas bases de serviços, além da ausência de custeio para o deslocamento para as reuniões dos colegiados e da criação de espaços lúdicos para as crianças durante as agendas do território (Butto; Hora, 2014:22).

De um modo geral, as expectativas e demandas levantadas pelas mulheres que vivem nos "territórios rurais" estão relacionadas a um conjunto de fatores interligados. Esses fatores estão, relacionados à esfera produtiva, passando pelas condições de infraestrutura no meio rural, pelo acesso a bens, serviços básicos e direitos de cidadania. A própria organização social da agricultura familiar e camponesa, demanda o atendimento às necessidades das mulheres como mães ao reivindicarem espaços 
para os seus filhos, chamando a atenção, assim, para as desigualdades de gênero.

Assim, em que pese todos os esforços no sentido de estimular a participação efetiva das mulheres na gestão dos seus respectivos "territórios", ela não foi potencializada. ${ }^{11}$ Ainda assim, não deixa de nos causar surpresa o fato de que mesmo durante os 12 anos de existência da SDT e da política territorial, as mulheres rurais não tenham conseguido serem sujeitos plenos dessa política. Sem querer aqui fazer uma avaliação da política em si, pretendemos trazer algumas reflexões sobre os limites que se impõem a um "território instituído" quando ele não é efetivamente construído pelas pessoas que ocupam o espaço por ele delimitado; $e$, no caso específico das mulheres, como isso pode ter limitado a participação delas no fortalecimento da política territorial. Ou seja, um território instituído como uma escala de ação adequada para empreender políticas públicas territoriais, mas não construído na prática cotidiana das mulheres que nele vivem, pode não ser reconhecido enquanto tal, limitando não apenas a participação das mulheres na sua gestão, como também ameaçando a própria existência do território tal como instituído pela política do Estado.

A dinamização das economias nos "territórios rurais" pode ser um bom ponto de partida para abordarmos essas questões, pois, como mencionado anteriormente, ela se constitui numa diretriz fundamental para o desenvolvimento territorial. A questão que se coloca é quanto à possibilidade da economia dos territórios rurais serem dinamizada sem considerar as dimensões relativas aos processos econômicos protagonizados por mulheres camponesas no interior das famílias e comunidades e na relação com outros segmentos sociais, a partir do seu cotidiano, das suas vivências e experiências através das quais os territórios são construídos.

\footnotetext{
${ }^{11}$ Lembre-se também que as ações previstas visando esse fim foram suspensas com o fim do Ministério do Desenvolvimento Agrário, em 2016.
} 
A fala abaixo nos mostra como a dimensão econômica da vida de mulheres e homens dos contextos rurais, alvos das mencionadas políticas públicas, está imbricada em outras dimensões e muito próxima a uma economia em que a "dádiva" é um princípio fundamental, que implica no dar, receber e retribuir (Mauss, 1974):

Se você for pegar a geração de riquezas, que a gente escuta quando fala em "desenvolvimento" também, a gente fala em solidariedade, e o que é solidário você sabe o que acontece né, tipo assim, é aquela troca: troca de experiências, produto por um produto, trabalho por trabalho. É solidário mesmo, e é o que a gente faz nas nossas comunidades, não tem aquela geração de riqueza enorme como em outro tipo de agricultura no caso, não sei se para a agricultura familiar a gente vê esta produção de riqueza aí que se fala (E.S., 37 anos, 2016).

As mulheres rurais trazem nas suas falas uma dimensão da economia que não implica necessariamente, ou tão somente, o princípio do cálculo, da produção de riquezas e a satisfação de interesses materiais individuais/privados e que correspondem bem ao espírito mercantil da troca.

Não adianta a gente ter relação de produção e de consumo e lá nas famílias as mulheres estão com o trabalho delas, ou, por exemplo, como acontece lá no Alto do Jequitinhonha, que é uma região de muito artesanato, que as mulheres fazem as bonecas maravilhosas, de barro, lindíssimas, lá perto de Turmalina e tudo mais, lá estamos cansados de saber que as mulheres fazem as bonecas, mas quem cuida do dinheiro e que pega as bonecas para aonde quer, é o homem. Às vezes participar de um projeto é ter mais trabalho. Então pra gente falar de economia de um território, a gente precisa falar de economia sem exploração, se falarmos de uma ampliação a gente precisa ter em mente que é preciso falar de uma economia que não seja sexista, que é uma economia que valoriza o trabalho 
doméstico e de cuidados e que também crie possibilidades para as mulheres se inserirem no trabalho mercantil (T. P., 41 anos, 2016).

O Projeto de Infraestrutura e Serviços em Territórios Rurais (PROINF) disponibiliza recursos não reembolsáveis e tem como principal objetivo apoiar projetos voltados para a dinamização das economias territoriais. Ele é executado pela SDT em parceria com os colegiados territoriais que indicam os projetos que representam demandas de infraestrutura e serviços. É, pois, no interior do colegiado territorial que se dá o embate sobre o direcionamento dos recursos. Trava-se ali um campo de forças pela disputa dos recursos. Para as mulheres, defender um projeto nesse espaço a fim de obter recursos depende da capacidade das mulheres agricultoras familiares, camponesas, em construir sua representação, tomar a palavra e consolidar um poder de decisão dentro desse espaço. Um espaço que segundo elas ainda é masculino.

A grande maioria dos territórios não tem participação da base do território aqui no estado. As instituições são priorizadas e sempre são mais os homens quem participa. Onde tem articulação de mulheres se conseguiu reconstruir o Comitê de Mulheres. A discussão do PROINF específico mesmo, a maioria nem enviou projeto, o valor é muito baixo, são municípios grandes e territórios gigantescos, como fazer com pouco recurso? (Z.M., 55 anos, 2016).

Lá no nosso território com a participação das mulheres, não existem mulheres nem no quadro técnico, é um problema muito sério, as mulheres estão para protagonizar, as mulheres estão para discutir, para fazer a proposta, mas na hora de ocupar o espaço, de estar junto ali, espaço de fato, espaço de poder, não tem mulheres. Não tem mulheres nas direções dos conselhos territoriais e não tem mulheres no quadro de técnicos também, nem no Núcleo Diretivo. Às vezes me pergunto se isso acontece porque as mulheres não estão procurando estes espaços, ou não estão ocupando 
estes espaços. O porquê elas são, digamos assim, um pouco desassistidas, excluídas destes espaços. Estes espaços são mesmo só para os homens e as mulheres não podem fazer parte?" (E. da S., 51 anos, 2016)

Essa ausência é em parte atribuída, pelas próprias entrevistadas, ao fato de as mulheres operarem com uma lógica própria na proposição de projetos, uma lógica que parece não se enquadrar na lógica instituída. Assim, elas por vezes preferem conseguir os recursos por outros meios, do que ter que enfrentar o processo de disputa, que segundo algumas delas, "cansa", é uma "queda de braço sem fim".

O acesso às políticas públicas para as mulheres... hoje, na hora do almoço, tinha um colega conversando que, tem política de crédito, mas a gente não acessa. A gente descobriu lá, que a gente não acessa as políticas de crédito, porque o que as mulheres... a lógica do projeto das mulheres não cabe, ela não cola na planilha do banco. Tem uma senhora que ela veste os filhos e ainda compra o material escolar vendendo ovo de galinha. Mas se ela pedir um projeto pra aumentar a produção dela, não é viável, porque só ela sabe a lógica dela, e funciona, e ela não está devendo e ainda mantém a família. Assim ela educou os filhos todinhos, mas pro banco isso não é possível. A mesma coisa se a gente quiser recursos pra construir instalações pra criação de galinha caipira, é recurso de infraestrutura né, tem que ser disputado, é uma peleja. (...) O mesmo é com assistência técnica, os técnicos, de assistência técnica, chegam nas propriedades, as mulheres chegam $e$ falam da sua vontade de fazer um projeto $e$ os técnicos sempre falam da inviabilidade econômica do projeto das mulheres, ou de que é um trem que não vai dá certo, ou de que não dá assistência técnica para o projeto das mulheres. Ou então se é um projeto, sei lá, com bois, com vacas, com um trem assim grande é o marido que sabe. As galinhas são das mulheres (E.S., 37 anos, 2016). 
Lá na Zona da Mata, é só ir nas comunidades e aí buscar as mulheres e os jovens... O que é que está acontecendo? Porque saem? Ahhh! Daí elas dizem: porque não tem opção de lazer, não tem lugar na unidade produtiva, não podemos fazer nada, não temos espaços, nossa posição é subordinada... Nós vamos ficar aqui? Não! E aí vão surgindo vários outros problemas. Eu acho que tem que primeiro entender o que significa este desenvolvimento territorial e esse território aí, e agora sim: eu me sinto parte dele, porque eu sei o que é, concordo, e vou defender este valor. Caso contrário, nós estamos defendendo uma coisa que não sabemos bem o que é: todo mundo está defendendo, então eu também vou defender, eu acho que não deve ser assim (A. M., 53 anos, 2016).

O desenvolvimento territorial como uma proposição que se apresenta de forma verticalizada, de cima para baixo, não tem conseguido incorporar as práticas cotidianas, as aspirações, vivências e experiências das mulheres, que assim resistem a, ou não encontram caminhos para, participar dos espaços de decisão e gestão dos planos de desenvolvimento dos territórios instituídos pelo Estado, embora sejam ativas tanto quanto os homens em seus territórios de vida e trabalho.

\section{Notas finais: a política de desenvolvimento territorial e questões não respondidas}

Quais são os indicadores de identidade e quais são os demarcadores de alteridade para os homens e mulheres alvos das políticas de desenvolvimento territorial rural? Sabe-se que a concepção política de desenvolvimento voltada para o espaço rural a partir de uma perspectiva territorial teve por propósito ser supralocal e supramunicipal. Mas sabe-se, igualmente, que as identidades são referidas a um lugar, assumindo importância o sentimento de pertencimento a um lugar. Nesse sentido, um dos desafios que deveria ter sido colocado para tais políticas, ao nosso ver, é o de perceber como diferentes coletivos ligados por uma multiplicidade de relações de trocas materiais e imateriais, 
constroem e definem os seus territórios e como "reelaboram os bens materiais $e$ imateriais adquiridos da intensificação da interação entre universos culturais distintos" (Carneiro; Rocha, 2007:8) compreendendo aí também as interações entre campo e cidade.

Como observado na primeira seção deste artigo, a noção de território possibilita superar o entendimento do lugar como "fixidez", permitindo entender, inclusive, que a circulação das pessoas entre contextos rurais e urbanos, e mesmo o fato de muitas terem suas vidas entre o campo $e$ a cidade, por razóes diversas como escassez de recursos, não implica na perda da importância do lugar. Muito já se alertou, entretanto, acerca da operacionalidade da noção de território quando transposto para o âmbito das políticas públicas. A atenção já foi chamada para o fato de que

o recurso a essa noção supõe, na maioria das vezes uma visão integradora, e talvez, excessivamente harmoniosa, não levando em conta as disputas de interesses entre os atores sociais e a possível manipulação dos argumentos (e imagens) com os quais são construídas as identidades territoriais (Carneiro; Rocha, 2007:9)

e somaríamos a essa crítica uma visão pouco dinâmica e demasiado sincrônica da territorialidade.

Além disso, alguns projetos revelaram uma externalidade da categoria quando empregada operacionalmente, o que em alguma medida contradiz o conceito mesmo de território entendido como processos de construção de espaços de vida inerentes aos grupos sociais. Para explicitar essa afirmação, recorremos a uma experiência trazida por Carneiro \& Rocha (2007), referente a um projeto para a:

...implantação de uma unidade agroecológica para beneficiamento do caqui (como carro-chefe), tomate $e$ maracujá envolvendo os municípios de Nova Friburgo, Sumidouro, Carmo e Duas Barras [...] O curioso, no 
entanto, é que dos quatro municípios envolvidos apenas Sumidouro e Nova Friburgo têm produção expressiva de caqui. Embora se constate a insignificância da produção dos outros dois municípios, a presença deles no projeto era considerada fundamental para a aprovação do mesmo dentro da nova abordagem territorial de desenvolvimento. Além disso, justifica o extensionista, era uma oportunidade para "treinarem o território" (Carneiro; Rocha, 2007:18, aspas no original).

A ideia de "treinar o território" revela o que estamos chamando de externalidade, aos próprios sujeitos da ação da política pública, como um aspecto recorrente em muitas situações do uso de território como categoria operatória. Daí deriva também um outro questionamento sobre a própria noção de desenvolvimento, que conforme o Marco Referencial para Apoio ao Desenvolvimento de Territórios Rurais (2005)

não é decorrência da ação verticalizada do poder público, mas sim a criação de condições para que os agentes locais se mobilizem em torno de uma visão de futuro, de um diagnóstico de suas potencialidades e constrangimentos, $e$ dos meios para perseguir um projeto próprio de desenvolvimento sustentável (MDA/SDT, 2005:9)

Apesar disso, o exemplo acima e também as últimas falas das mulheres apresentadas na seção precedente mostram a persistência de uma lógica operacional da política "de cima para baixo" para a aprovação nas instâncias decisórias. Carneiro e Rocha vão mostrar ainda, para o caso do referido projeto de implantação de uma unidade agroecológica, que há também entraves decorrentes de "uma cultura política que inibe a participação dos agricultores em espaços de concertação entre atores sociais com interesses distintos". Podemos agregar a essa observação a desigualdade de gênero na participação nas políticas de desenvolvimento territorial, agudizada por não se levar em conta a agenda das mulheres e o seu protagonismo na economia familiar. 
Por fim, valem algumas palavras a mais sobre as ideias de desenvolvimento. Nota-se que as falas das mulheres trazidas neste artigo fazem uma crítica ao desenvolvimento atrelado a uma noção produtivista e de mercado, ao tempo em que evocam redes de relações solidárias, como vimos na seção anterior:

se você for pegar a geração de riquezas, que a gente escuta quando fala em 'desenvolvimento' também, a gente fala em solidariedade, e o que é solidário você sabe o que acontece né, tipo assim, é aquela troca: troca de experiências, produto por um produto, trabalho por trabalho (E.S.,37 anos, 2016).

Essas falas evocam algumas observações feitas por $\mathrm{M}$. Sahlins (2007) ao refletir sobre o sistema mundial e especialmente sobre a economia mundial capitalista e sua capacidade de "reduzir as propriedades sociais a valores de mercado" (Sahlins, 2007:450). Lembra o autor a fala de um melanésio que, ao inserir o termo inglês "development' em uma frase em pidgin soou algo como "develop-man", aludindo à ideia de desenvolvimento do que "as pessoas consideram digno dos seres humanos" (Sahlins, 2007:448). Enunciadas em contextos tão distintos, essas falas remetem à noção de desenvolvimento referida ao ser humano e a uma ética de relacionamentos $e$ não apenas a uma dimensão econômica que a tudo precifica. Eis mais uma boa questão colocada por mulheres e homens dos nossos campos e ainda não respondida.

\section{Referências bibliográficas}

AgUiAR, V. V. P. Somos todas margaridas: um estudo sobre o processo de constituição das mulheres do campo e da floresta como sujeito político. Tese (Doutorado em Ciências Sociais) - Programa de PósGraduação em Ciências Sociais, Universidade Estadual de Campinas, Campinas, 2015.

. Desenvolvimento Territorial. Impacto das políticas públicas para as mulheres rurais: limites e desafios. Relatório Técnico. Projeto IICA/SEAD, Brasília-DF, 2016. 
Bonnal, P.; Cazella, A. A.; Delgado, N. G. Contribuições ao estudo do desenvolvimento territorial rural: reflexões metodológicas a partir do caso brasileiro. Biblio $3 W$, Revista Bibliográfica de Geografía y Ciencias Sociales Universidad de Barcelona, 17, $\mathrm{n}^{\circ}$ 1002, Barcelona, 2012 [www.ub.edu/geocrit/b3w-1002.htm - acesso em 07 out. 2016]

BRAH, Avtar. Diferença, diversidade, diferenciação. cadernos pagu (26), Campinas/SP, Núcleo de Estudos de Gênero-Pagu/Unicamp, 2006, pp.329-376.

. Cartografías de la diáspora: identidades en cuestión. Madrid, Traficantes de Sueños, 2011 [1996].

BRASIL. Ministério do Desenvolvimento Agrário. Secretaria de Desenvolvimento Territorial. Territórios da cidadania: proposta do Ministério do Desenvolvimento Agrário para redução da desigualdade social no meio rural brasileiro. Brasília-DF, MDA, 2007.

BUTLER, Judith. Fundamentos contingentes: o feminismo e a questão do "pós-modernismo". cadernos pagu (11), Campinas/SP, Núcleo de Estudos de Gênero-Pagu/Unicamp, 1998, p.11-42.

Problemas de gênero: feminismo e subversão da identidade. 2.ed. Rio de Janeiro, Civilização Brasileira, 2003. [Tradução: Renato Aguiar].

ButTo, Andrea et alii (org.). Mulheres rurais e autonomia: formação e articulação para efetivar políticas públicas nos Territórios da Cidadania. Brasília-DF, Ministério do Desenvolvimento Agrário, 2014.

ButTo, Andrea. Mulheres no Desenvolvimento territorial. In: DELGADO, Nelson G. (org.). A política de desenvolvimento do Brasil Rural, Brasília-DF, Ministério do Desenvolvimento Agrário, 2010, pp.214231.

CARNEIRO, Maria José; RoCHA, Betty Nogueira. As cercas (in) visíveis da patronage: limites e possibilidades da construção de territórios de desenvolvimento. Seminário Temático 26, $31^{\circ}$ Encontro da ANPOCS, Caxambu-MG, 2007 [http://www.anpocs.com/index.php/encontros/papers/31-encontroanual-da-anpocs/st-7/st26-3/3060-mariacarneiro-as-cercas/file acesso em 15 ago. 2017] 
CONDRAF. Resolução No 80, de 19 de maio de 2011, Diário Oficial da União (DOU) de 08/07/2011, Brasília-DF, Seção I, pp.94-95.

CORRÊA. Vanessa Petrelli. Desenvolvimento Territorial e a Implantação de Políticas Públicas Brasileiras Vinculadas a esta Perspectiva. Boletim Regional, Urbano e Ambiental n 3, Brasília-DF, IPEA, dez. 2009, pp.23-37.

CostA, Cláudia Lima. O feminismo e o pós-modernismo/pósestruturalismo: (in)determinações da identidade nas (entre)linhas do (con)texto. In: PEDRO, Joana Maria; GROSSI, Miriam Pillar (orgs.). Masculino, feminino, plural: gênero na interdisciplinaridade. Florianópolis: Editora Mulheres, 2000, pp.57-90.

GRISA, Cátia. Projetos Estratégicos e Ações Para o Desenvolvimento Territorial: uma análise do PRONAT e do programa territórios da Cidadania. In: LEITE, Sérgio Pereira (org.). Políticas de Desenvolvimento Territorial e Enfrentamento da Pobreza Rural no Brasil. Série Desenvolvimento Rural Sustentável, vol. 19, Brasília, 2013, pp.149-176.

HAESBAERT, Rogério. O mito da desterritorialização: do fim dos territórios à multiterritorialidade. Rio de Janeiro-RJ, Bertrand Brasil, 2009 [2004].

HALL, Stuart. Quem precisa de identidade? In: SILVA, Tomás Tadeu da (org). Identidade e diferença: a perspectiva dos estudos culturais. 9.ed. Petrópolis, RJ, Vozes, 2009, pp.103-131.

LefeBVRE, Henri. La production de l'espace. Paris, Anthropos, coll. Ethnosociologie, 2000 [1974].

LEITE, Sérgio Pereira et alii. Desenvolvimento Territorial: articulação de políticas públicas e atores sociais. In: MiRANDA, Carlos; TiBURCiO, Breno (orgs.). Articulação de Políticas Públicas e Atores Sociais. Brasília, DF, IICA, Série Desenvolvimento Rural Sustentável, vol. 8, 2008, pp.69-169.

LITTE, Paul E. Territórios sociais e povos tradicionais no Brasil: por uma antropologia da territorialidade. Brasília-DF, Série Antropologia $\mathrm{n}^{\circ}$ 322, Editora UnB, 2002. 
MAUSS, Marcel. Ensaio sobre a dádiva. Forma e razão da troca nas sociedades arcaicas. São Paulo, Sociologia e Antropologia, EPU/EDUSP, vol. II, 1974.

MDA/SDT. Marco Referencial para Apoio ao Desenvolvimento de Territórios Rurais, Série Documentos Institucionais, Brasília, DF, 2005 [http://sge.mda.gov.br/bibli/documentos/tree/doc_214-28-11-201211-32-675117.pdf - acesso em: 10 set 2018]

PIETRAFESA DE GODOI, Emília. Territorialidade: trajetórias e usos do conceito. Raízes, Revista de Ciências Sociais e Econômicas, vol. 34, $\mathrm{n}^{\circ}$ 2, Campina Grande, PB, UFCG, julho-dez. 2014, pp.08-16.

RAFFestin, Claude. Por uma geografia do poder. São Paulo, Ática, 1993 [1980].

. Repères pour une théorie de la territorialité humaine. In: DUPUY, G. (org), Résseaux Térritoriaux, Caen, Paradigme, 1988.

SACK, Robert. Human territoriality: its theory and history. Cambridge, Cambridge University Press, 1986.

SAHLINS, Marshall. O 'pessimismo sentimental' e a experiência etnográfica: por que a cultura não é um 'objeto' em via de extinção, Revista Mana 3, Rio de Janeiro-RJ, Programa de Pós-Graduação em Antropologia Social do Museu Nacional/UFRJ, 1997, pp.41-73(1) e pp.103-150(2).

- Cosmologias do Capitalismo: o setor transpacífico do sistema mundial, Cultura na Prática. $2^{\text {a }}$ ed. Rio de Janeiro, Editora da UFRJ, 2007.

ScotT, Joan. Gênero: uma categoria útil de análise histórica. Educação \& Realidade, Porto Alegre, vol. 20, n 2, jul./dez. 1995, pp.71-99

SiLIPRANDI, Emma; CINTRÃO, Rosangela. Mulheres e Políticas no Brasil: abrindo espaços para o seu reconhecimento como cidadãs. In: GRISA, Cátia; SCHNEIDER, Sérgio (orgs.). Politicas Públicas de Desenvolvimento Rural no Brasil, Porto Alegre, Série Estudos Rurais, Editora da UFRGS, 2015, pp.571-592

SOF; CF8. Diagnóstico sobre a implementação das políticas públicas para a igualdade de gênero do MDA na reforma agrária e agricultura familiar. São Paulo, SOF Sempreviva Organização Feminista, Centro Feminista 8 de Março - CF8, 2010. 
TIMM, Ervanda. Documento contendo proposições para articulação e integração com programas e diretrizes governamentais de planejamento para o fortalecimento da estratégia de Desenvolvimento Territorial e Pronat, IICA, Brasília-DF, 2014 [http://www.iicabr.iica.org.br/wpcontent/uploads/2014/03/Produto_6_2013_Ervanda-1 - acesso em: 30 ago. 2017]. 